\title{
Antifungal Activity of Actinomycetes from Vermicompost and Their Morphological and Biochemical Characterization
}

\author{
Rishi Baniya and Gita S. Vaidya \\ Nepal Academy of Science and Technology (NAST) Khumaltar, Lalipur \\ e-mail: rishi1baniya2@yahoo.com
}

\begin{abstract}
Thirty eight actinomycetes were isolated from saw dust and husk containing vermicompost samples. Of them, four (10.5\%) were active against at least one of the tested phytopathogenic fungi; Fusarium oxysporum, F.moniliforme, F. proliferatum, Stemphylium botryosum, Exserohilum turcicum and human pathogenic fungi; Candida albicans and Aspergillus spp. during dual culture method. Of them, VAH3 showed broad spectrum activity against both pathogenic fungi with maximum inhibition of $24.53 \pm 0.20 \%$ against $F$. oxysporum and minimum inhibition of 12.37 $\pm 0.24 \%$ against Stemphylium botryosum on solid agar surface. In agar well diffusion method, only VAH3 showed broad spectrum activity with maximum inhibition diameter of $14 \mathrm{~mm}$ against $F$. proliferatum and minimum inhibition diameter of six mm against Sclerotium rolfsii. Among them, one promising strain Streptomyces VAH3 was selected for further study. The minimum inhibitory concentrations of crude antifungal agent against F. oxysporum, Stemphylium botryosum, and Exserohilum turcicum, Candida albicans and Aspergillus spp. were found to be 560 $\mu \mathrm{g} / \mathrm{ml}, 1120 \mu \mathrm{g} / \mathrm{ml}, 1120 \mu \mathrm{g} / \mathrm{ml}, 560 \mu \mathrm{g} / \mathrm{ml}$ and $1120 \mu \mathrm{g} / \mathrm{ml}$, respectively. Morphological, biochemical and physiological tests confirmed that all four potent strains were from Streptomyces genus.
\end{abstract}

Key words: actinomycete strains, F. oxysporum, vermicompost, Streptomyces spp.

\section{Introduction}

Root rot disease of lentil, caused by Fusarium oxysporum $\mathrm{f}$. sp lentis is one of the important diseases of the world. In Nepal, this disease and Stemphylium blight disease, caused by Stemphylium botryosum, at the early stage of plant growth cause heavy loss in lentil productivity (Joshi 2010). Similarly, Exserohilum turcicum cause heavy loss of maize productivity due to northern leaf blight disease.

The management of Fusarium root rot and wilting disease of lentil is very difficult because no single treatment is fully effective. Currently, solarization of soil, advance sowing date, use of disease free seeds and fungicide-treated seeds are in practice but with limited success (Jalali \&Chand 1992; Haware \&Nene 1982). Although the use of resistant cultivar is the most economical and efficient control measure, the evolution of variability in pathogenicity of these pathogens has caused difficulty in controlling diseases (Haware \&Nene 1982, Jimenez-Gasco \&Jimenez-Diaz 2003). The coordinated varietal trial experiment carried out in 45 lines of lentil crop at 
Rampur, Chitwan and Khajura (Banke) showed 30 lines resistant, 5 moderately resistant and 10 susceptible to Fusarium root rot (Joshi 2010).

Biological treatments of these soil borne fungal phytopathogens by using different bacterial antagonists such as Pseudomonas spp., Bacillus spp. and fungal antagonists such as Trichoderma spp. were effective in different parts of the world. However, Trichoderma koningi was not effective in controlling root rot of lentil in Nepal (Joshi 2010).

Vermicomposts are rich source of beneficial microorganisms which not only degrade organic macromolecules into simpler forms but also help control phytopathogenic and human pathogenic diseases by producing secondary metabolities such as antibiotics, chitinase enzymes, siderophores and Indole acetic acid and other phenol containing compounds. In this study, actinomycetes from vermicompost were screened for antifungal activity against phytopathogenic fungi and human pathogenic fungi, Aspergillus sps and Candida albicans, and potent strains were characterized morphologically, biochemically and physiologically.

\section{Methodology}

\section{Preparation of vermicompost}

Two combinations of vermicomposts: a) Sawdust (100g): Chopped straw (100g): Mixed vegetable and fruit wastes (100g), and b) Husk (100g): Chopped Straw (100g): Mixed vegetable and fruit wastes (100g) were prepared in $10 \mathrm{~L}, 5-6$ holed plastic buckets at room temperature in Nepal Academy of Science and Technology premises. The bedding materials were moistened with water and placed inside the bottom of bucket. Then, the crushed mixed vegetable and fruit wastes were composted on the top of bedding materials using 100 earthworms in each bucket covered with lid. Hundred grams mixture of vegetable and fruit wastes was added once a week as feed for earthworms. The whole set up was kept for 3 months until all the wastes were completely digested.

\section{Isolation}

One gram mature vermicompost sample from each combination was suspended in $9 \mathrm{ml}$ sterile distilled water and further serial dilution was performed up to $10^{-6}$. Dilutions from $10^{-4}-10^{-6}$ were spread plated onto Starch Casein Agar (SCA) and incubated at $28^{\circ} \mathrm{C}$ for 7 days (Collins et al. 1989).

\section{Screening of antifungal activity}

Antifungal activity of actinomycetes against phytopathogenic fungi (Fusarium oxysporum, F. proliferatum, F. moniliforme, F. eridiforme, Stemiphylium botryosum, Exserohilum turcicum and Sclerotium rolfsii) and human pathogenic fungi (Aspergillus sps and Candida albicans) was performed on potato dextrose agar by dual culture method (Crawford et al. 1993). Secondary screening of potent strains was further performed by using agar well diffusion method as described elsewhere (Barry \&Thornsberry 1985).

\section{Characterization of active actinomycetes}

Morphological, biochemical and physiological characterization of active actinomycete isolates were performed as described elsewhere (Williams et al. 1989).

\section{Extraction of antifungal agent}

The extraction of antifungal agents was performed as described elsewhere (Augustine et al. 2004).

\section{Determination of Minimum inhibitory concentration (MIC)}

The minimum inhibitory concentrations of crude antifungal agent and standard antifungal antibiotic Nystatin were determined against F. oxysporum, $S$. botryosum, E. turcicum, Candida albicans and Aspergillus spp as described elsewhere (NCCLS 2002).

\section{Results and discussion}

Altogether 38 actinomycetes were isolated from sawdust and husk containing vermicomposts. Among 
them, four (10.5\%) isolates were found to be effective against at least one of the tested phytopathogenic fungi by dual culture method. Isolate VAH3 showed broad spectrum activity with maximum inhibition of $24.53 \pm 0.20 \%$ against $F$. oxysporum and minimum inhibition of $12.37 \pm 0.24 \%$ against Stemphylium botryosum. Isolates VAH1, VAH8 and VAS9 inhibited all tested Fusarium sps but did not show activity against Stemphylium botryosum and Exserohilum turcicum. (Table 1)

Table 1. Antifungal activity of actinomycetes (\% inhibition)

\begin{tabular}{|c|c|c|c|c|}
\hline $\begin{array}{l}\text { Isolates } \\
\text { Fungi }\end{array}$ & VAH1 & VAH3 & VAH8 & VAS9 \\
\hline F. oxysporum & $8.11 \pm 0.11$ & $24.53 \pm 0.20$ & $10.05 \pm 1.0$ & $12.40 \pm 0.23$ \\
\hline F. moniliforme & $12.25 \pm 0.14$ & $21.10 \pm 0.64$ & $12.90 \pm 0.33$ & $12.33 \pm 0.33$ \\
\hline F. proliferatum & $12.15 \pm 0.15$ & $23.80 \pm 0.57$ & $12.66 \pm 0.38$ & $12.66 \pm 0.38$ \\
\hline$F$. eridiforme & $12.60 \pm 0.35$ & $23.75 \pm 0.38$ & $12.99 \pm 0.33$ & $12.20 \pm 0.20$ \\
\hline Stemphylium botryosum & - & $12.37 \pm 0.24$ & - & - \\
\hline Exserohilum turcicum & - & $12.66 \pm 0.38$ & - & - \\
\hline
\end{tabular}

Morphological, biochemical and physiological tests of potent strains confirmed that all four isolates were from Streptomyces genus (Figure 1 \& Table 2). All four isolates were found to possess gram positive recti-flexibilis type of sporophores originating from branching thin mycelium during microscopy. Biochemical tests like sugar utilization tests, Nitrate reduction and polysaccharide hydrolysis tests and physiological tests such as temperature and Sodium chloride tolerance tests showed high variability among these four isolates as well as those of reported species in Bergey's Manual of Systemic Bacteriology Vol. IV. Streptomyces VAH3 is more than 70\% similar to Streptomyces noursei. Although it is difficult to ascertain unknown isolates to their species level based on biochemical and physiological tests only, these tests are still useful to know the diversity of particular genera in natural samples.
Of four active strains, only Streptomyces VAH3 showed broad spectrum activity against tested phytopathogenic and human pathogenic fungi during secondary screening. It showed more than $10 \mathrm{~mm}$ inhibition diameter against $F$. oxysporum, $F$. moniliforme, F. eridiforme, Stemphylium botryosum, Apergillus spp., and Candida albicans (human pathogenic yeast) and no inhibition against Sclerotium rolfsii (Table 3). These results showed that antibiotic production occurred better in solid agar surface culture than in shake flask culture without rigorous optimization. Earlier studies also showed that agar surface culture was favorable for screening antibiotic production because of gradual availability of a key nutrient at suboptimal level and slight change in $\mathrm{pH}$ (Martin and Aharonowitz, 1983; Nisbet, 1982). 
Nepal Journal of Science and Technology 12 (2011) 97-102

Table 2. Morphological, biochemical and physiological characterization of potent actionmycetes

\begin{tabular}{|c|c|c|c|c|}
\hline Characteristics & $\mathrm{VAH1}$ & $\mathrm{VAH}$ & VAH8 & VAS9 \\
\hline Aerial mycelium color & CW & CW & $\mathrm{G}$ & CW \\
\hline Substrate mycelium color & W & B & W & W \\
\hline Spore chain & RF & RF & RF & RF \\
\hline Soluble pigment & + & + & - & - \\
\hline Catalase & + & + & + & + \\
\hline Oxidase & - & - & - & - \\
\hline Nitrate reduction & - & + & + & + \\
\hline Sulphur & - & + & - & - \\
\hline Urea degradation & - & + & - & + \\
\hline D-Gulcose & + & + & + & + \\
\hline D-Fructose & + & + & - & + \\
\hline L-arabincese & - & + & + & + \\
\hline Glycogen & - & - & - & - \\
\hline D-xylose & - & + & + & + \\
\hline Raffinose & - & + & + & - \\
\hline Sucrose & - & + & - & + \\
\hline Galactose & - & + & + & - \\
\hline Lactose & - & + & + & - \\
\hline D-Marunitol & - & + & - & - \\
\hline D-Mannose & - & + & - & - \\
\hline Esculin & + & + & + & + \\
\hline Salicin & - & - & - & - \\
\hline Starch hydrolysis & + & + & + & + \\
\hline Ge latin hydrolysis & + & + & + & + \\
\hline Casein hydrolysis & + & + & + & + \\
\hline Tween 20 hydrolysis & + & + & + & + \\
\hline Chitin hydrolysis & - & + & - & + \\
\hline $5 \% \mathrm{NaCl}$ & + & + & - & - \\
\hline $7 \% \mathrm{NaCl}$ & + & + & - & - \\
\hline $10 \% \mathrm{NaCl}$ & - & - & - & - \\
\hline $4^{\circ} \mathrm{C}$ & - & - & - & - \\
\hline $28^{\circ} \mathrm{C}$ & + & + & + & + \\
\hline $37^{\circ} \mathrm{C}$ & + & + & - & - \\
\hline $45^{\circ} \mathrm{C}$ & - & - & - & - \\
\hline
\end{tabular}

CW, Creamy white; W, White; RF, Rectus-flexibilis, ;B, Brown; G, Grey 
Rishi Baniya \& Gita S. Vaidya/Antifungal Activity........

Morphological, biochemical and physiological tests of potent strains confirmed that all four isolates were from Streptomyces genus (Figure 1 \& Table 2). All four isolates were found to possess gram positive rectiflexibilis type of sporophores originating from branching thin mycelium during microscopy. Biochemical tests like sugar utilization tests, Nitrate reduction and polysaccharide hydrolysis tests and physiological tests such as temperature and Sodium chloride tolerance tests showed high variability among these four isolates as well as those of reported species in Bergey's Manual of Systemic Bacteriology Vol. IV. Streptomyces VAH3 is more than $70 \%$ similar to Streptomyces noursei. Although it is difficult to ascertain unknown isolates to their species level based on biochemical and physiological tests only, these tests are still useful to know the diversity of particular genera in natural samples.
Of four active strains, only Streptomyces VAH3 showed broad spectrum activity against tested phytopathogenic and human pathogenic fungi during secondary screening. It showed more than $10 \mathrm{~mm}$ inhibition diameter against $F$. oxysporum, $F$. moniliforme, F. eridiforme, Stemphylium botryosum, Apergillus spp., and Candida albicans (human pathogenic yeast) and no inhibition against Sclerotium rolfsii (Table 3). These results showed that antibiotic production occurred better in solid agar surface culture than in shake flask culture without rigorous optimization. Earlier studies also showed that agar surface culture was favorable for screening antibiotic production because of gradual availability of a key nutrient at suboptimal level and slight change in $\mathrm{pH}$ (Martin and Aharonowitz, 1983; Nisbet, 1982).

Table 3. Antifungal activity of Streptomyces VAH3 against phytopathogenic fungi

\begin{tabular}{llc}
\hline Isolate & Phytop athogenic fungi & Zone of inhbition diameter (mm) \\
\hline Streptomyces & F. oxysporum & $11(5)$ \\
VAH3 & F. moniliforme & $11(5)$ \\
& F. proijferatum & $14(5)$ \\
& F. eridiforme & $10(5)$ \\
Sclerotium rolfsii & $6(5)$ \\
& Stemphyium botryosum & $10(5)$ \\
& Candida albicans & $10(5)$ \\
& Aspergillus spp. & $12(5)$ \\
& Exserohilum turticum & $10(5)$ \\
\hline
\end{tabular}

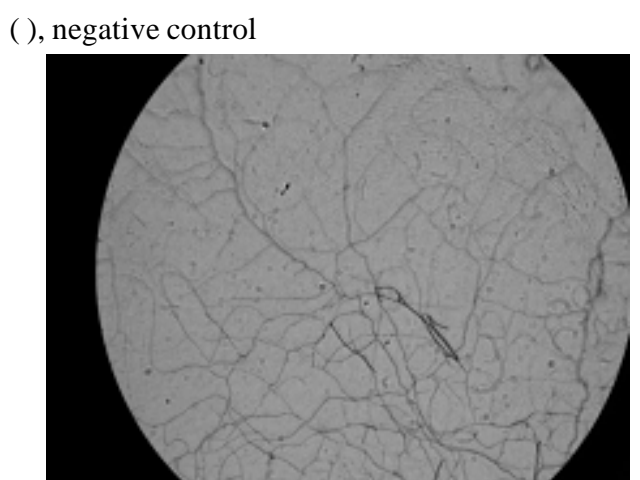

Fig. 1. Recti- flexibilis sporophore of Streptomyces VAH3 originating from thin mycelium under $100 \mathrm{X}$ oil immersion

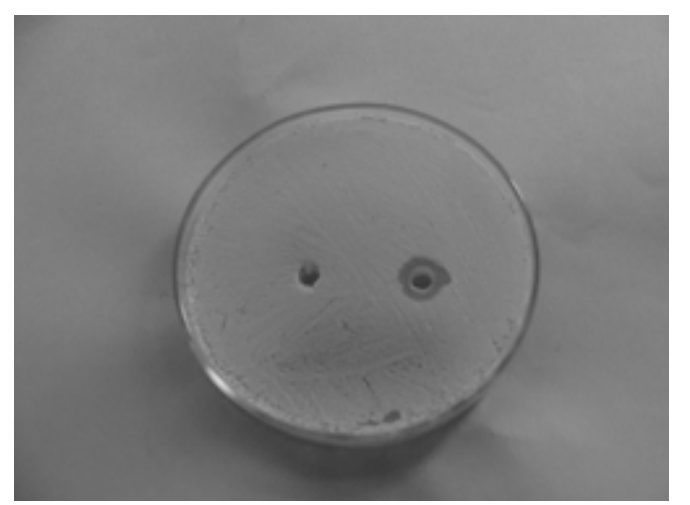

Fig. 2. Antifungal activity of Streptomyces VAH3 broth (162 $\mu \mathrm{g} / 100 \mu \mathrm{l})$ against Candida albicans 


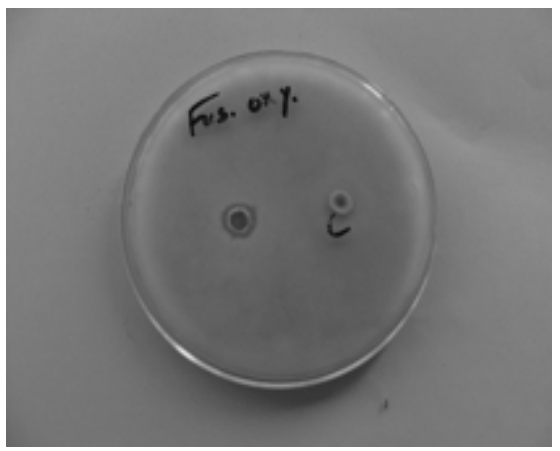

Fig. 3. Antifungal activity of Streptomyces VAH3 broth $(162 \mu \mathrm{g} / 100 \mu \mathrm{l})$ against Fusarium oxysporum
Among four solvents; benzene, chloroform, ethyl acetate and n-butanol used for the extraction of antifungal agent, only ethyl acetate extract showed activity against both phytopathogenic and human pathogenic fungi. The ethyl acetate extract yield was found to be $162 \mathrm{mg}$ per $100 \mathrm{ml}$ of fermented broth. The minimum inhibitory concentrations of crude antifungal agents against $F$. oxysporum, E. turcicum, $S$. botryosum Candida albicans, Aspergillus spp. were found to be $560 \mu \mathrm{g} / \mathrm{ml}, 112 \mu \mathrm{g} / \mathrm{ml}, 112 \mu \mathrm{g} / \mathrm{ml}, 560 \mu \mathrm{g}$ / $\mathrm{ml}$ and $112 \mu \mathrm{g} / \mathrm{ml}$ respectively and that of Nystatin (positive control) was found to be $64 \mu \mathrm{g} / \mathrm{ml}$ for each of tested pathogenic fungi (Table 4).

Table 4. Minimum inhibitory concentrations of ethyl acetate extract of Streptomyces VAH3 against pathogenic fungi

\begin{tabular}{|c|c|c|c|c|c|}
\hline $\begin{array}{l}\text { Antifungal } \\
\text { agents }\end{array}$ & \multicolumn{5}{|c|}{$\begin{array}{l}\text { Minimm inhbitory concentrations ( } \mu \text { g/nI) } \\
\text { F. oxysporum E. tuxcicum } S . \text { botryosum. C. ab̈icans Aspergïhs spp }\end{array}$} \\
\hline $\begin{array}{l}\text { Ethyd acetate } \\
\text { extract }\end{array}$ & 560 & 1120 & 1120 & 560 & 1120 \\
\hline Nystatin & 64 & 128 & 128 & 64 & 128 \\
\hline
\end{tabular}

\section{Acknowledgements}

We thank Nepal Academy of Science and Technology (NAST) for providing space and resources to conduct this research in Biotechnology Laboratory. We also thank Plant Pathology Division of Nepal Agricultural Research Council for providing phytopathogenic fungi and Microbiology Department, Institute of Medicine, Maharajgunj for providing human pathogenic fungi.

\section{References}

Augustine, S. K., S. P. Bhavsar, M. Baserisalehi and B. P. Kapandnis. 2004. Isolation, characterization and optimization of antifungal activity of an actinomycete of soil origin. Indian Journal of Experimental Biology 42: 928-932.

Barry, A. L. and C. Thornsberry. 1985. Susceptibility tests: Diffusion test procedure. In: Manual of Clinical Microbiology (Ed. E. H. Lennette). $4^{\text {th }}$ ed. American Society of Microbiology, Pp. 978-987.

Collins, C. H., P. M. Lyne and J. M. Grange. 1989. Microbiological methods. $6^{\text {th }}$ ed. Butterworth-Heinemann Ltd., Pp. 495-410.

Crawford, D. L., J. M. Lynch, J. M. Whipps and M. A. Ousley. 1993. Isolation and characterization of actinomycetes antagonsists of a fungal root pathogen. Applied and Environmental Microbiology 59 (11): 3899-3905.
Haware, M. P. and Y. L. Nene. 1982. Races of Fusarium oxysporum f. sp. ciceri. Plant Diseases 66: 809-810.

Jalali, B. L. and H. Chand. 1992. Chickpea wilt. In: Plant diseases of international importance. Diseases of Cereals and Pulses (Eds. U. S. Singh \& K. A. Mukhopadhaya). Prentice Hall, Eaglewood cliff, Pp. 429-449.

Jimenez-Gasco, M. M. and R. M. Jimenez-Diaz. 2003. Development of a specific polymerase chain reaction-based assay for the identification of Fusarium oxysporum $\mathrm{f}$. sp.cicer and its pathogenic races $0,1 \mathrm{~A}, 5$ and 6 . Phytopathology 93: 200-209.

Joshi, S. 2010. Lentil. Annual Report. Plant Pathology Division, National Agricultural Research Institute, Kumaltar, Lalitpur, Nepal, Pp. 45-49.

Martin, J. F. and Y. Aharonowitz. 1983. Regulation of biosynthesis of b-lactam antibiotics. In: Antibiotics containing the beta lactam structure (Eds. A. L. Demain \& N. A. Solomon). Springer-Verlag, Berlin, Pp. 229-254.

NCCLS, 2002. Reference method for broth dilution antifungal susceptibility testing of filamentous fungi. Approved standard. NCCLS document M38-A. Clinical and Laboratory Standards Institute Villanova, Pa.

Nisbet, L. J. 1982. Current strategies in the search for bioactive microbial metabolites. Journal of Chemical Technology and Biotechnology 32: 251 -270.

Williams, S. T., M. Goodfellow and G. Alderson. 1989. Genus Streptomyces Waksman and Henrici 1943, 339AL. In: Bergey's Manual of Systematic Bacteriology (Eds. S.T. Williams, M.E. Sharpe \& J. G. Holt). Williams and Wilkins, Baltimore 4: 2452-2492. 